\title{
Impacto do conceito de empacotamento de partículas na dosagem de concretos de alto desempenho
}

\author{
Impact of particle packing concept on \\ dosage of high performance concrete
}

\author{
Caroline Oliveira e Oliveira ${ }^{1}$, Geraldo de Freitas Maciel ${ }^{1}$, \\ Alessandra Lorenzetti de Castro ${ }^{2}$, Mônica Pinto Barbosa ${ }^{1}$, \\ Renan Serralvo Campos ${ }^{1}$
}

\author{
${ }^{1}$ Universidade Estadual Paulista (UNESP - Ilha Solteira), CEP 15385-000, Ilha Solteira, SP \\ e-mail: carololiveira.eng@gmail.com, maciel@dec.feis.unesp.br, monica_eng_civil@yahoo.com.br, re- \\ nan_serralvo@hotmail.com \\ ${ }^{2}$ Universidade de São Paulo (USP - São Carlos), CEP 13566-590, São Carlos, SP \\ e-mail: alcastro@sc.usp.br
}

\section{RESUMO}

O concreto de alto desempenho (CAD) é um material que apresenta características específicas, como alta resistência à compressão e elevada durabilidade. Para que esse concreto atenda às suas características específicas, uma cuidadosa seleção e dosagem dos seus componentes devem ser realizadas. Desta forma, este trabalho buscou contribuir com o estudo de dosagem do CAD, utilizando o conceito de empacotamento de partículas, onde foi determinada a proporção ótima dos componentes particulados a partir do modelo de Alfred, também conhecido como modelo de Andreasen modificado. Realizada a dosagem do CAD, analisou-se a influência do empacotamento de partículas no seu desempenho mecânico e nas propriedades reológicas da pasta de cimento e argamassa constituintes do CAD. O CAD otimizado, com base no conceito de empacotamento de partículas, apresentou, aos 28 dias, resistência à compressão satisfatória, podendo ser classificado como um concreto de alta resistência, e superior à resistência à compressão do CAD de referência. Na caracterização reológica da pasta de cimento e argamassa, o emprego do empacotamento provocou um aumento da fluidez, facilitando o escoamento, sem prejudicar a estabilidade da mistura de concreto.

Palavras-chave: Concreto de alto desempenho, Dosagem, Empacotamento de partículas, Reologia.

\begin{abstract}
High performance concrete (HPC) is a material that has specific characteristics, such as high compressive strength and high durability. In order for this concrete to meet its specific characteristics, a careful selection and dosage of its components must be carried out. Thus, this paper aims to contribute with HPC dosage study using the concept of particle packing, where the optimal proportion of particulate components was determined by Alfred model, also known as modified Andreasen model. Held the dosage of the HPC, was analyzed the influence of particle packing on its mechanical performance and on the rheological properties of the cement paste and mortar HPC constituents. The optimized HPC based on particle packing concept presented satisfactory compressive strength at 28 days, which can be classified as a high strength concrete, and superior compressive strength to the reference HPC. In the rheological characterization of cement paste and mortar, the use of packing concept caused an increase of the fluidity, facilitating the flow, without harming the stability of concrete mix.
\end{abstract}

Keywords: High performance concrete, Mix design, Particle packing, Rheology.

\section{INTRODUÇÃO}

O concreto de alto desempenho (CAD) é um tipo de concreto especial aplicado nas estruturas, sendo suas principais características a alta resistência à compressão e a elevada durabilidade. A alta resistência à compressão permite a redução da seção transversal dos elementos estruturais, resultando em economia de materi- 
al, enquanto sua maior durabilidade prolonga a vida útil das estruturas e, consequentemente, reduz os custos com sua manutenção. Assim, o uso desses concretos vem crescendo ao longo dos últimos anos, em diversos países do mundo.

Para produzir o CAD de acordo com as especificações supracitadas, é necessário aplicar conceitos da engenharia de microestrutura. Por serem compósitos constituídos de partículas com dimensões reduzidas e uma baixa relação água/aglomerante, esses materiais apresentam matrizes densas obtidas a partir da otimização do sistema granular, enquanto a trabalhabilidade adequada é obtida com a dispersão das partículas pela incorporação de aditivos químicos. Assim, uma cuidadosa seleção e dosagem dos seus componentes devem ser realizadas e, dentre os diversos procedimentos e métodos existentes de dosagens de concretos especiais, pode-se destacar o uso dos conceitos de reologia e de empacotamento de partículas.

\subsection{Reologia dos materiais à base de cimento}

A reologia, ciência voltada ao estudo da deformação e do fluxo da matéria, atravessa vários séculos e abrange diversos campos do conhecimento. A aplicação dos conceitos de reologia pode englobar diferentes materiais, entre eles os materiais à base de cimento, como as pastas, argamassas e concretos que, quando no estado fresco, se comportam como fluidos.

Dada a grande influência que a pasta de cimento exerce sobre o comportamento reológico dos concretos no estado fresco, diversos autores [1-4] consideram vantajoso conhecer suas características reológicas antes de se discutir as características reológicas do concreto. Além disso, o estudo reológico de pastas de cimento e argamassas pode ser utilizado para selecionar e otimizar aditivos químicos e adições minerais, fornecendo informações úteis para a dosagem de concretos. Entretanto, a reologia deve ser aplicada corretamente; caso contrário, o material poderá sofrer modificações que afetarão o seu desempenho [5].

As últimas décadas foram profícuas para a pesquisa no campo da reologia dos materiais à base de cimento, devido ao uso crescente de aditivos químicos e adições minerais em misturas de concreto com consistência plástica a fluida. O comportamento reológico desses materiais tem sido estudado por diversos pesquisadores, contribuindo com o desenvolvimento e aperfeiçoamento de técnicas de caracterização reológica aplicáveis na dosagem e no controle de qualidade de pastas, argamassas e concretos [1-10].

A avaliação dos parâmetros reológicos do concreto não é uma tarefa simples, devido à grande variedade de tamanho de partículas encontradas nessa dispersão (desde partículas menores que $1 \mu \mathrm{m}$, até maiores que dezenas de milímetros) [11]. Além disso, há outra dificuldade associada com a determinação do comportamento reológico do concreto, que é a necessidade de reômetros com capacidade de acomodar partículas "grandes", algumas vezes com dimensão maior que $20 \mathrm{~mm}$ [12-13]. No entanto, equipamentos com dimensões suficientemente grandes, cada qual com sua especificidade e limitação, têm sido construídos, possibilitando a construção das curvas de cisalhamento desses materiais [14-16].

No Brasil, pesquisadores têm promovido avanços no campo da reologia de materiais à base de cimento, fazendo com que ele seja cada vez mais explorado, destacando-se, por exemplo, sua aplicação no estudo de otimização de aditivos químicos e adições minerais incorporados às misturas de concreto, uso e aplicação da reometria clássica e de técnicas alternativas para a determinação de parâmetros reológicos de pastas de cimento e argamassas constituintes das misturas de concreto [17-19], entre outros. Porém, a investigação das propriedades reológicas diretamente no concreto ainda não é comum no país.

Em 1948, Robert L'Hermite e Tournon apresentaram os primeiros estudos sobre reologia do concreto no estado fresco [20]. Desde então, várias pesquisas vêm sendo desenvolvidas para caracterizar reologicamente esse material, porém os métodos de ensaio existentes não determinam propriedades reológicas semelhantes para um mesmo concreto. As variações devem-se principalmente às diferentes técnicas experimentais empregadas e aos equipamentos utilizados [16]. Além disso, a maioria dos métodos são geralmente complicados, requerem habilidade e não são facilmente realizados em campo.

Do ponto de vista reológico, um material é bem caracterizado de acordo com a relação entre tensão de cisalhamento e a taxa de cisalhamento. Para suspensões concentradas, como os materiais à base de cimento, notadamente as pastas, tenta-se correlacionar a concentração da suspensão com um indicador de viscosidade, assumindo, assim, que exista apenas um indicador ou valor de viscosidade para todo o sistema [11]. Se tal propositura é usada para descrever, preferencialmente, o comportamento do escoamento de pastas de cimento, esta não é aplicável ao concreto em função da complexidade da suspensão. Assim, para argamassas e concretos, adotam-se as melhores correlações (curvas de fluxo) oriundas dos diversos espectros tensão de cisalhamento versus taxas de cisalhamento, conforme apresentado na Tabela 1. O modelo reológico mais adequado dependerá, certamente, da composição do material. Vale ressaltar que tal procedimento não exclui a análise das próprias pastas de cimento, conforme adotado neste artigo. 
Tabela 1: Modelos reológicos aplicados aos materiais cimentícios no estado fresco e suas respectivas equações.

\begin{tabular}{c|c|c}
\hline Fluido & Modelo reológico & Equação do modelo \\
\hline Newtoniano & Newton & $\tau=\mu \tilde{y}$ \\
\hline Não-newtoniano & Bingham & $\tau=\tau_{0}+\mu_{B} \dot{\gamma}$ \\
\hline Não-newtoniano & Herschel-Bulkley & $\tau=\tau_{0}+k_{n} \dot{\gamma}^{n}$ \\
\hline Não-newtoniano & Lei das potências & $\begin{array}{c}\tau=k_{n} \dot{\gamma}^{n} \\
n=1, \text { para fluido newtoniano } \\
n>1, \text { para fluido dilatante } \\
n<1, \text { para fluido pseudoplástico }\end{array}$ \\
\hline
\end{tabular}

Nota: $\tau=$ tensão de cisalhamento; $\tau_{0}=$ tensão limite de escoamento; $\mu=$ viscosidade; $\mu_{B}=$ viscosidade

plástica; $\tilde{\gamma}=$ taxa de cisalhamento; $n=$ índice de escoamento; $k_{\mathrm{n}}=$ índice de consistência.

Segundo FERRARIS et al. [1], as propriedades de escoamento da pasta de cimento podem ser semelhantes às de um fluido newtoniano ou de um fluido binghamiano (não newtoniano), dependendo do estado de dispersão das partículas. Já o concreto, por ser um sistema particulado mais complexo, além de exigir a imposição de uma tensão ou força mínima para que ele inicie seu escoamento (existência de tensão limite de escoamento), vai exibir, consequentemente, curva de escoamento ou de fluxo que não passará pela origem, e não necessariamente, dependência linear entre tensão aplicada e taxas de cisalhamento. Na literatura, devido a uma vasta evidência experimental das propriedades de escoamento do concreto no estado fresco, verifica-se que os modelos reológicos mais adequados para descrever o comportamento desses materiais são os modelos de Bingham e de Herschel-Bulkley [7, 11, 18, 21, 22].

No que diz respeito a técnicas de medida, a reometria rotacional consiste de um conjunto de procedimentos, cujos ensaios fornecem os dois parâmetros fundamentais para a descrição do comportamento reológico - viscosidade plástica e tensão limite de escoamento - dos materiais à base de cimento, especialmente dos concretos exibindo comportamento binghamiano. Os ensaios reométricos são totalmente automatizados e controlados por computador e software dedicado, onde são plotadas as curvas de escoamento e de viscosidade aparente versus taxa de deformação. A partir dessas curvas, o modelo reológico é ajustado e os parâmetros fundamentais são determinados.

\subsection{Empacotamento de partículas para a produção de concretos}

Nos últimos anos, o conceito de empacotamento de partículas tem despertado o interesse das diferentes áreas da engenharia, uma vez que grande parte dos materiais naturais ou industriais utilizados diariamente são, ou contêm, partículas de diferentes formas e tamanhos [23]. Assim, o comportamento de tais materiais depende parcialmente das propriedades das partes que o compõem e parcialmente das interações entre elas.

O estudo do empacotamento de partículas pode ser definido como o problema da correta seleção da proporção e do tamanho adequado dos materiais particulados, de forma que os vazios maiores sejam preenchidos por partículas menores, cujos vazios serão novamente preenchidos com partículas ainda menores e, assim, sucessivamente [24]. Em 1892, Féret publicou o primeiro tratado sobre o empacotamento de partículas em concreto e, desde então, diversos modelos de empacotamento têm sido propostos como ferramenta para calcular a densidade de empacotamento das partículas e, assim, otimizar misturas granulares de concretos [25, 26].

Para suspensões concentradas, como o concreto, o projeto da distribuição do tamanho de partículas é de fundamental importância, pois promove o empacotamento e, juntamente com o fluido, define suas características reológicas durante o processo de mistura, quando no estado fresco [24-26]. O conceito de uma alta densidade de empacotamento foi recentemente redescoberto como um parâmetro chave para a obtenção de concretos com desempenho mecânico e durabilidade superiores, graças à utilização simultânea de aditivos químicos e adições minerais [27].

Os modelos de empacotamento de partículas se apresentam através de equações matemáticas que prescrevem como partículas de diferentes tamanhos irão interagir geometricamente. Tais modelos calculam a densidade de empacotamento teórica de uma mistura baseado na distribuição granulométrica e na densidade de empacotamento de um determinado grupo de partículas. Dentre os modelos disponíveis na literatura, o modelo de Alfred, também conhecido como modelo de Andreasen modificado (Equação 1), proposto por FUNK e DINGER [28], se destaca na dosagem de concretos por possuir maior eficiência de empacotamento e ser mais condizente com sistemas particulados reais. 


$$
\operatorname{CPFT}(\%)=\left(\frac{D^{q}-D_{S}^{q}}{D_{L}^{q}-D_{S}^{q}}\right) \times 100
$$

onde CPFT é a porcentagem acumulada de partículas menores que o diâmetro $\mathrm{D}, \mathrm{D}_{\mathrm{S}}$ é o diâmetro da menor partícula, $\mathrm{D}_{\mathrm{L}}$ o diâmetro da maior partícula, e q é o coeficiente ou módulo de distribuição.

Na prática, uma das formas de se determinar o melhor empacotamento de partículas é o estabelecimento de curvas granulométricas ideais por meio dos modelos de empacotamento. Tendo-se uma curva ideal (teórica), busca-se uma combinação entre as partículas dos materiais disponíveis de forma a se aproximar o máximo possível desta curva ideal. Isso pode ser feito de maneira simples, por meio da otimização computacional (método dos mínimos quadrados e Simplex, por exemplo) do sistema granular constituinte da mistura, com o auxílio de planilhas eletrônicas [29, 33, 34].

No caso da abordagem por curvas ideais, é necessário definir um valor para o coeficiente de distribuição (q) em função do tipo de concreto que se pretende produzir. No modelo de Alfred, a máxima densidade de empacotamento ocorre quando o valor de q é igual a 0,37. No entanto, em suspensões contendo partículas finas e grossas, como o caso dos concretos, um coeficiente de distribuição igual a 0,37 não proporciona a máxima fluidez do sistema, dado que os agregados se encontram muito próximos e a interferência entre eles é elevada, pois dispõe de pouca matriz para seu afastamento [24]. Para que os concretos apresentem boa capacidade de escoamento recomenda-se que o valor do coeficiente de distribuição seja inferior a 0,30: valores próximos a 0,30 devem ser considerados para misturas adensadas sobre vibração, enquanto valores entre 0,20 e 0,25 resultam em misturas autoadensáveis [30]. O efeito da redução do valor do coeficiente de distribuição se dá no aumento da quantidade de finos, que influencia a interação entre as partículas.

De uma forma geral, no caso de partículas esféricas, o empacotamento aleatório de monodispersões resulta sempre em um mesmo fator de empacotamento. Porém, a forma das partículas dos materiais granulares que comumente compõem as misturas de concreto está distante de uma esfera e deve-se admitir que, tradicionalmente na tecnologia dos concretos, pouca atenção é dada à busca por uma distribuição granulométrica ótima dessas partículas. Além disso, ao estudar o comportamento dos concretos depara-se com um problema relacionado com a garantia de se reproduzir materiais com distribuição granulométrica precisa, isto é, as matérias-primas nem sempre apresentam uma distribuição granulométrica contínua e reprodutível ao longo do tempo.

Uma simples análise convencional dos teores de cimento e de agregados não é suficiente para tornar reprodutíveis os concretos produzidos com as diversas matérias-primas existentes. A sistematização do processo de dosagem exige um maior rigor na técnica de combinação das matérias-primas para que a mistura das mesmas represente efetivamente a distribuição estudada teoricamente [31]. No caso particular do concreto, o processo de dosagem baseado no conceito de empacotamento de partículas tem sido alvo de vários pesquisadores [23, 25, 27, 32, 33]. Em suas pesquisas, os autores procuraram desenvolver e avaliar modelos de empacotamento de partículas para otimização dos componentes granulares dos concretos, de maneira a se obter misturas com alta densidade de empacotamento, ou seja, com baixa porosidade e, consequentemente, com elevada resistência à compressão e durabilidade, enquanto a trabalhabilidade adequada é alcançada por meio da dispersão das partículas promovida pela incorporação de aditivos químicos à mistura.

Em estudo desenvolvido por CASTRO et al. [33], os autores verificaram que concretos dosados com base no conceito de empacotamento de partículas apresentaram-se trabalháveis por um período de tempo maior quando do estado fresco, sem a necessidade da incorporação de aditivos retardadores, enquanto no estado endurecido, apresentaram uma maior resistência mecânica aos 28 dias quando comparado a concretos de alto desempenho dosados por meio de métodos tradicionais de dosagem.

\subsection{Justificativa}

Os conceitos de reologia e de empacotamento de partículas parecem seguir caminhos distintos no processo de dosagem dos concretos: enquanto o primeiro procura otimizar os teores de aditivos químicos e adições minerais, de maneira a se obter a trabalhabilidade adequada por meio da dispersão das partículas, o segundo visa otimizar os materiais particulados constituintes da mistura de concreto a partir da distribuição granulométrica de partículas. Porém, a associação de ambos os conceitos é de grande importância para a dosagem dos concretos, procurando obter misturas que atendam, da melhor forma possível, os requisitos relacionados aos diferentes tipos de concreto.

Apesar de diversos trabalhos [17, 27, 33, 34] já terem sido ou estejam sendo desenvolvidos sobre o 
tema - dosagem de concretos especiais com base nos conceitos de dispersão e empacotamento de partículas ainda é preciso realizar estudos nessa área a fim de consolidar a importância e a aplicação desses conceitos na construção civil. Segundo TUTIKIAN e HELENE [20], o uso da reologia no estudo de dosagem dos concretos ainda não convenceu o meio técnico da sua efetiva utilidade, enquanto o conceito de empacotamento de partículas para a produção de concretos é pouco conhecido pela maioria dos arquitetos e engenheiros atuantes na construção civil brasileira [35].

Assim, este trabalho buscou aplicar o conceito de empacotamento de partículas na otimização de concretos de alto desempenho, com o objetivo de obter matrizes mais densas e, portanto, com maior resistência mecânica. As propriedades de concretos otimizados com base nesse conceito são apresentadas e comparadas àquelas de concretos de alto desempenho dosados a partir dos conceitos de reologia.

\section{MATERIAIS E MÉTODOS}

O esquema geral do procedimento experimental realizado neste trabalho é apresentado na Figura 1, sendo detalhado em sequência.

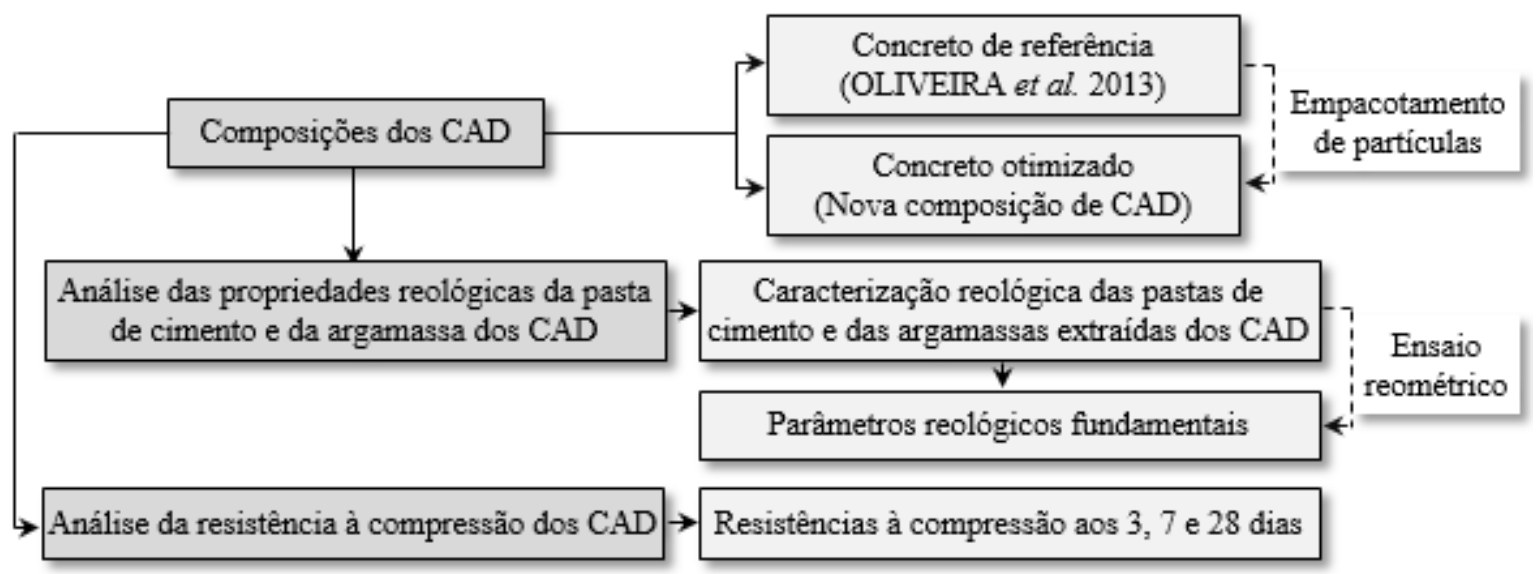

Figura 1: Esquema do procedimento experimental realizado neste trabalho.

\subsection{Materiais}

O cimento utilizado nas composições do concreto de referência e do concreto otimizado com base no conceito de empacotamento de partículas foi o cimento Portland composto com escória granulada de alto forno e classe de resistência de $32 \mathrm{MPa}$ aos 28 dias (CP II E 32), com massa específica de 3,05 g/cm $\mathrm{cm}^{3}$.

Para a produção do concreto de referência, foram utilizados como agregados a brita 1 de origem basáltica, com massa específica de $2,87 \mathrm{~g} / \mathrm{cm}^{3}$, e a areia natural média, com massa específica de $2,62 \mathrm{~g} / \mathrm{cm}^{3}$. O módulo de finura e a dimensão máxima desses agregados foram, respectivamente, 6,60 e $19 \mathrm{~mm}$ para a brita 1 e 2,02 e 4,75 mm para a areia média. Na composição do concreto otimizado com base no conceito de empacotamento de partículas, além dos materiais citados anteriormente, foram utilizados os seguintes agregados: pedrisco (massa específica de $2,81 \mathrm{~g} / \mathrm{cm}^{3}$ ), pó de pedra (massa específica de $2,87 \mathrm{~g} / \mathrm{cm}^{3}$ ) e areia industrial fina (massa específica de $2,64 \mathrm{~g} / \mathrm{cm}^{3}$ ).

A adição mineral utilizada nas composições dos concretos foi a sílica ativa não-densificada, com massa específica de $2,40 \mathrm{~g} / \mathrm{cm}^{3}$. O aditivo químico utilizado foi o superplastificante de terceira geração à base de éter policarboxílico e a água utilizada foi proveniente da rede de abastecimento local.

\subsection{Composições dos concretos de alto desempenho}

O concreto de referência, composto por cimento, brita 1, areia natural média, sílica ativa, superplastificante e água, foi elaborado por OLIVEIRA et al. [36] a partir do estudo reológico da pasta de cimento e da argamassa de uma composição inicial de CAD, estabelecia por REIS [37], a fim de determinar os teores ótimos de sílica ativa e de aditivo superplastificante incorporados à mistura de concreto.

Uma nova composição de CAD foi elaborada com base no conceito de empacotamento de partículas com o propósito de se obter maior densidade de empacotamento, no entanto, com fluidez adequada, proporcionando o aumento da resistência à compressão. 
A partir da distribuição granulométrica discreta dos materiais utilizados no concreto de referência (Figura 2a) foi possível verificar a ausência de determinados tamanhos de partículas. Assim, outros materiais (pedrisco, pó de pedra e areia industrial fina) foram selecionados para a produção da nova composição de CAD a fim de melhorar o empacotamento das partículas (Figura 2b).

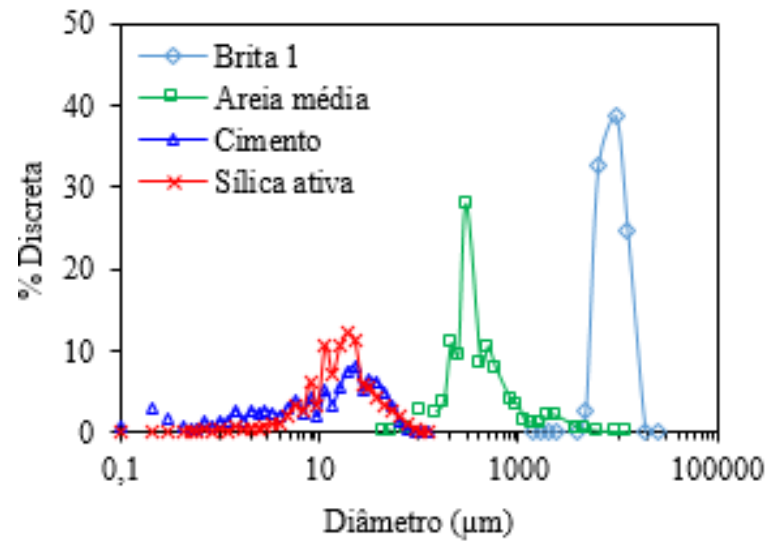

(a)

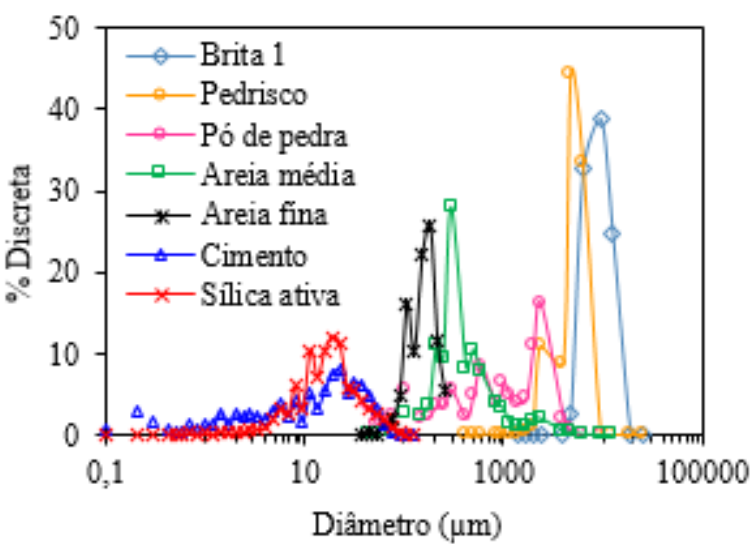

(b)

Figura 2: Distribuição granulométrica discreta dos materiais: (a) CAD referência e (b) CAD empacotamento.

A nova composição de CAD consistiu na otimização dos componentes granulares do concreto de referência empregando o conceito de empacotamento de partículas por meio do modelo de Alfred. Inicialmente, o modelo de empacotamento (modelo de Alfred) foi aplicado no concreto de referência, obtendo, assim, o coeficiente de distribuição (q), que foi mantido constante para a nova composição de CAD. Após a definição do coeficiente de distribuição, foram inseridos, no modelo de empacotamento, os novos materiais selecionados, e realizado o ajuste da curva de distribuição granulométrica gerada à curva de distribuição granulométrica ideal do modelo de Alfred, determinando, deste modo, a proporção ótima dos materiais particulados do novo concreto.

Definida a proporção ótima dos materiais particulados, o teor de água/materiais secos da nova composição de CAD foi mantido igual ao do concreto de referência e o teor de aditivo superplastificante foi ajustado realizando sucessivas adições de aditivo durante o procedimento de mistura do concreto (Figura 3 ) até que o valor do abatimento, realizado conforme a NBR NM 67:1998 [38], estivesse dentro do intervalo de abatimento proposto $(160 \mathrm{~mm} \pm 20 \mathrm{~mm})$, igual para os dois concretos.

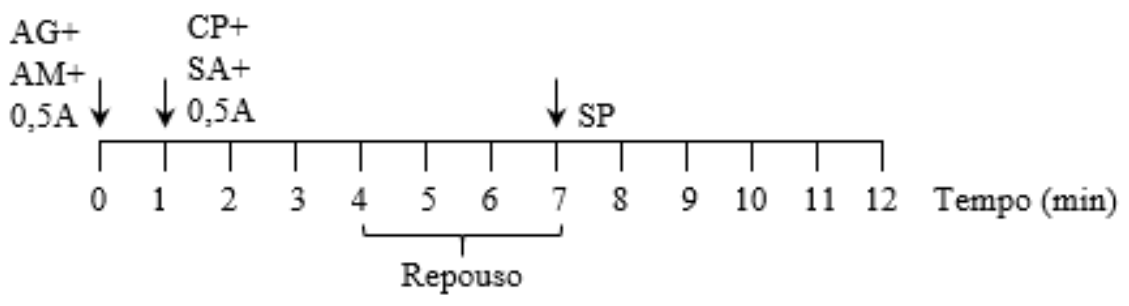

Figura 3: Procedimento de mistura dos concretos de alto desempenho, onde $\mathrm{AG}=$ agregado graúdo, $\mathrm{AM}=$ agregado miúdo, $\mathrm{A}$ = água, $\mathrm{CP}=$ cimento, $\mathrm{SA}=$ sílica ativa e $\mathrm{SP}=$ aditivo superplastificante.

\subsection{Análise das propriedades reológicas das pastas de cimento e das argamassas dos concretos de alto desempenho}

Foi realizada a caracterização reológica das pastas de cimento e das argamassas do concreto de referência e do concreto otimizado com base no conceito de empacotamento de partículas, com o objetivo de analisar e comparar os parâmetros reológicos, verificando a influência do empacotamento de partículas.

O ensaio utilizado para a caracterização reológica das pastas e argamassas foi o ensaio reométrico, que permite determinar os parâmetros reológicos fundamentais: viscosidade e tensão limite de escoamento.

\subsubsection{Caracterização reológica das pastas de cimento}


As composições das pastas de cimento foram extraídas das composições do concreto de referência e do concreto otimizado com base no conceito de empacotamento de partículas. O procedimento de mistura das pastas de cimento foi realizado conforme a sequência apresentada na Figura 4.

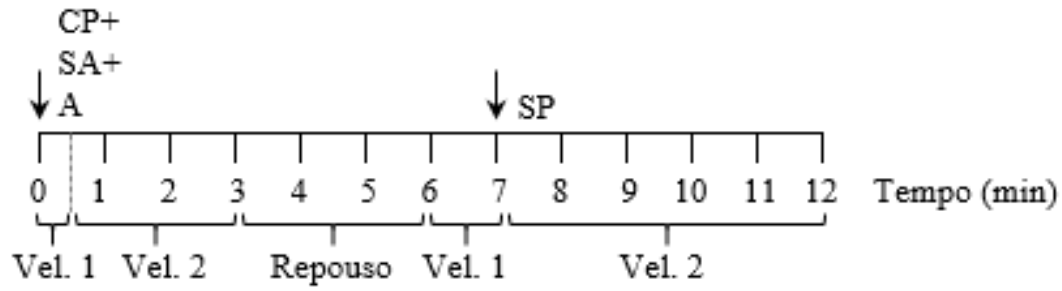

Figura 4: Procedimento de mistura das pastas de cimento, onde $\mathrm{CP}=$ cimento, $\mathrm{SA}=$ sílica ativa, $\mathrm{A}=$ água, $\mathrm{SP}=$ aditivo superplastificante, Vel. 1 e Vel. 2 = velocidade 1 (lenta) e 2 (rápida) da argamassadeira.

O ensaio reométrico das pastas de cimento, esquematizado na Figura 5, foi realizado ao longo do tempo, após 5, 15 e 30 minutos do instante de incorporação do superplastificante à mistura, sendo empregado para a caracterização reológica o reômetro R/S Brookfield do tipo cilindros coaxiais, com controle de temperatura $\left(24 \pm 1^{\circ} \mathrm{C}\right)$. Este tipo de reômetro pode ser utilizado tanto controlando a taxa de deformação e medindo a tensão de cisalhamento correspondente (análise CSR), como controlando a tensão de cisalhamento e medindo a taxa de deformação resultante (análise CSS). Para a caracterização reológica das pastas de cimento deste estudo foi realizada a análise CSS, gerando, assim, as curvas de escoamento (tensão de cisalhamento versus taxa de deformação) das amostras analisadas, com ajuste do modelo reológico fornecido diretamente pelo software Rheo2000.

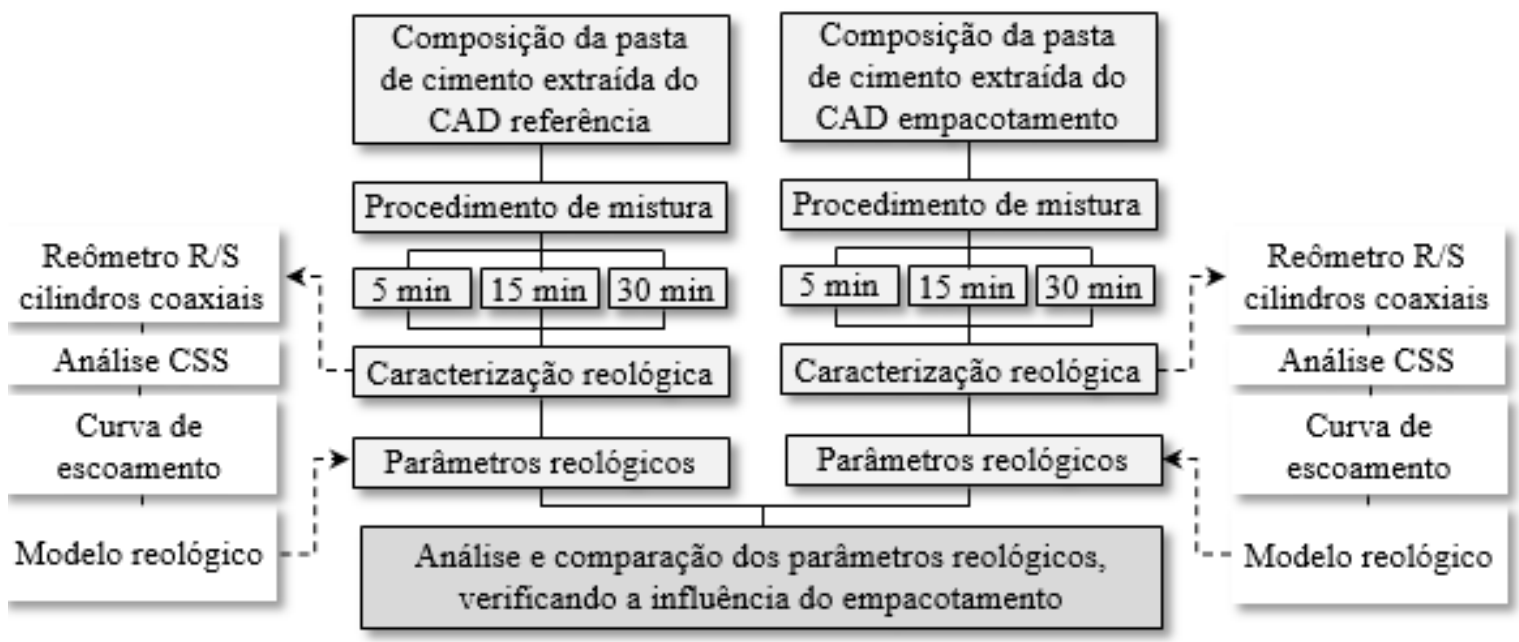

Figura 5: Esquema do ensaio reométrico das pastas de cimento.

\subsubsection{Caracterização reológica das argamassas}

Assim como as pastas de cimento, as composições das argamassas também foram extraídas das composições do concreto de referência e do concreto otimizado com base no conceito de empacotamento de partículas. $\mathrm{O}$ procedimento de mistura das argamassas foi realizado conforme a sequência apresentada na Figura 6.

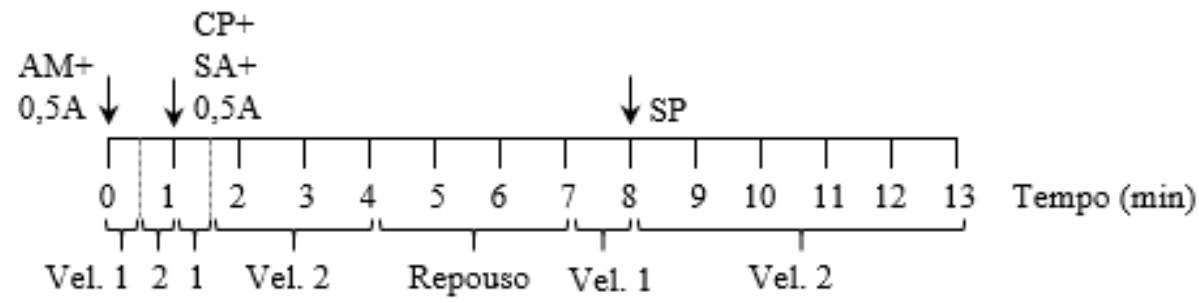


Figura 6: Procedimento de mistura das argamassas, onde $\mathrm{AM}=$ agregado miúdo, $\mathrm{A}=$ água, $\mathrm{CP}=$ cimento, $\mathrm{SA}=$ sílica ativa, SP = aditivo superplastificante, Vel. 1 e Vel. 2 = velocidade 1 (lenta) e 2 (rápida) da argamassadeira.

Para as argamassas, o ensaio reométrico, esquematizado na Figura 7, foi realizado após 5, 30 e 60 minutos do instante de incorporação do superplastificante à mistura, sendo empregado para a caracterização reológica o mesmo reômetro utilizado nas pastas de cimento, porém como a argamassa é composta por partículas maiores foi utilizado o sistema Vane, ao invés dos cilindros coaxiais, resguardada a análise CSS para a caracterização reológica da mesma.

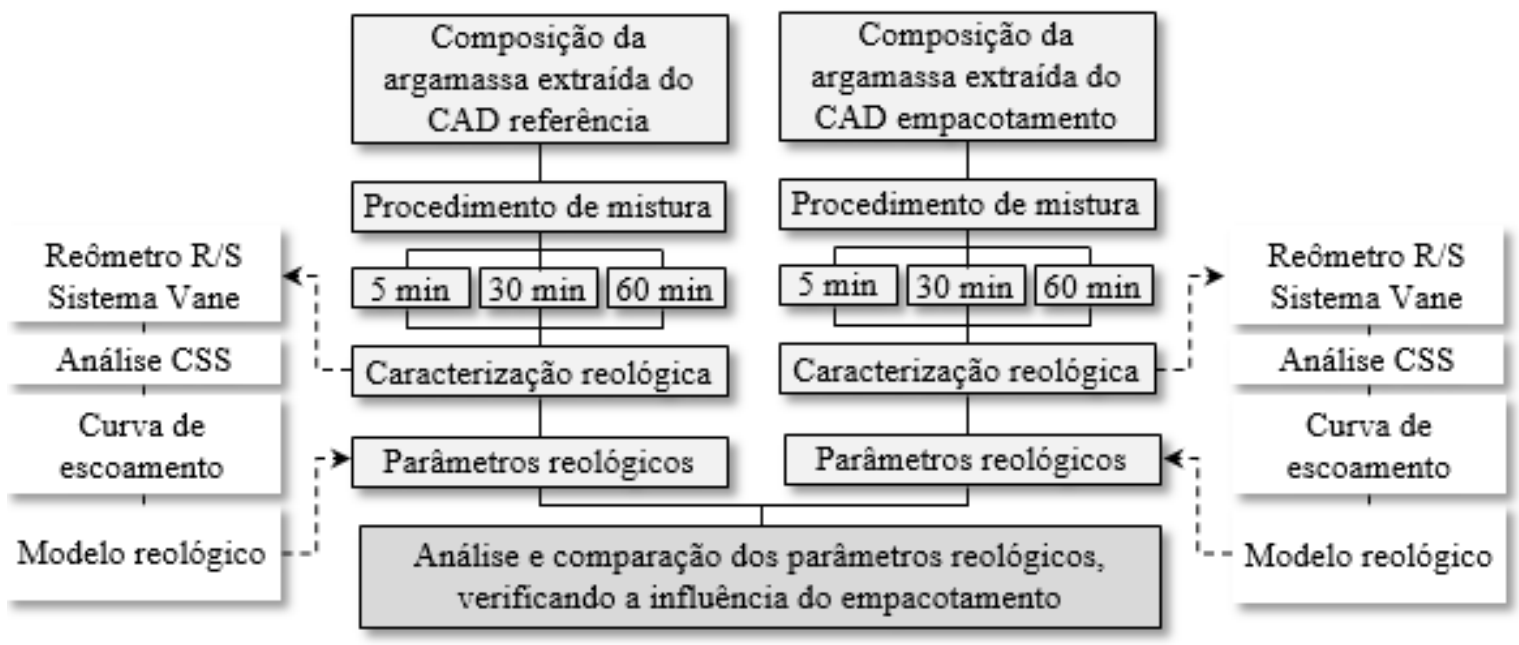

Figura 7: Esquema do ensaio reométrico das argamassas.

\subsection{Análise da resistência à compressão dos concretos de alto desempenho}

A resistência à compressão do concreto de referência e do concreto otimizado, com base no conceito de empacotamento de partículas, foi determinada ao longo do tempo, nas idades de 3, 7 e 28 dias, conforme a NBR 5739:2007 [39]. Foram analisadas as evoluções da resistência à compressão das composições de concreto de alto desempenho, verificando a influência do empacotamento de partículas.

Para a determinação da resistência à compressão foram moldados três corpos de prova cilíndricos (100 mm x $200 \mathrm{~mm}$ ) para cada idade analisada. Os corpos de prova permaneceram em cura úmida até as idades de ensaio.

\section{RESULTADOS E DISCUSSÕES}

\subsection{Composições dos concretos de alto desempenho}

A composição do concreto de referência é apresentada na Tabela 2. Considerando a distribuição granulométrica discreta de seus materiais particulados (Figura 2a) foi aplicado o modelo de empacotamento (modelo de Alfred) e determinada a curva de distribuição granulométrica do concreto de referência, apresentada na Figura 8. O coeficiente de distribuição obtido foi igual a 0,29 (adequado para concretos adensados sob vibração, como exposto por VANDERLEI [30]) e a porosidade teórica igual a 21,7\% em volume. 
Tabela 2: Composição do concreto de referência.

\begin{tabular}{c|c|c|c|c|c}
\hline \multicolumn{6}{c}{ Consumo de materiais $\left(\mathrm{kg} / \mathrm{m}^{3}\right.$ de concreto) } \\
\hline \multirow{2}{*}{ Cimento } & \multirow{2}{*}{$\begin{array}{c}\text { Sílica } \\
\text { ativa }\end{array}$} & Agregado miúdo & Agregado graúdo & \multirow{2}{*}{ Água } & \multirow{2}{*}{$\begin{array}{c}\text { Aditivo } \\
\text { superplastificante }\end{array}$} \\
\cline { 3 - 4 } & Areia média & Brita 1 & 160,1 & 4,67 \\
\hline 466,7 & 51,8 & 763,1 & 1088,6 & 160 \\
\hline
\end{tabular}

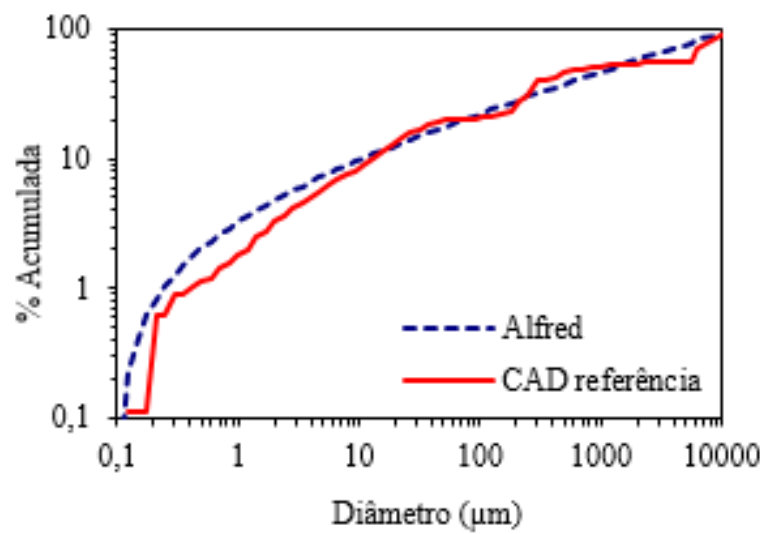

Figura 8: Curva de distribuição granulométrica do CAD referência, $q=0,29$.

Para a determinação da proporção ótima dos materiais particulados da nova composição de CAD foi empregado o modelo de Alfred considerando a distribuição granulométrica discreta de seus materiais particulados (Figura 2b) e mantendo constante o valor do coeficiente de distribuição obtido no concreto de referência $(q=0,29)$. A Figura 9 apresenta a curva de distribuição granulométrica do CAD otimizado com base no conceito de empacotamento de partículas.

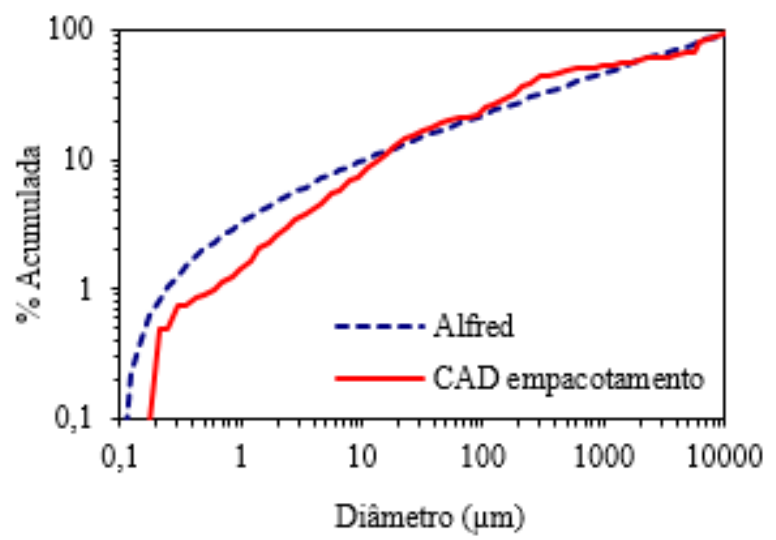

Figura 9: Curva de distribuição granulométrica do CAD empacotamento, para q =0,29.

Observa-se na Figura 9 que a curva de distribuição granulométrica da nova composição de CAD foi ajustada de forma a se aproximar o máximo possível da curva de distribuição ideal do modelo de Alfred, obtendo a proporção ótima de cada material particulado (Tabela 3), resultando em uma porosidade teórica igual a 12,2\% em volume. Vale ressaltar que houve dificuldade na otimização das partículas devido à falta de materiais com granulometrias adequadas necessárias, principalmente na fração mais fina, conforme observado no intervalo de 0,1 a $10 \mu \mathrm{m}$, onde a curva de distribuição granulométrica está mais afastada da curva teórica. Porém, mesmo com essa falha na parte fina da distribuição granulométrica, a nova composição de CAD apresentou porosidade teórica menor em relação ao concreto de referência. 
Tabela 3: Proporção dos materiais particulados dos concretos de alto desempenho.

\begin{tabular}{c|c|c}
\hline Materiais particulados & $\begin{array}{c}\text { CAD referência } \\
\% \text { peso }\end{array}$ & $\begin{array}{c}\text { CAD empacotamento } \\
\% \text { peso }\end{array}$ \\
\hline Brita 1 & 45,9 & 30,0 \\
\hline Pedrisco & ---- & 10,0 \\
\hline Pó de pedra & ---- & 15,0 \\
\hline Areia natural média & 32,2 & 15,0 \\
\hline Areia industrial fina & ---- & 10,0 \\
\hline Cimento & 19,7 & 15,0 \\
\hline Sílica ativa & 2,2 & 5,0 \\
\hline
\end{tabular}

Definida a proporção ótima dos materiais particulados da nova composição de concreto, foi realizado o ajuste do teor de aditivo superplastificante, mantendo-se fixo o teor de água/materiais secos em $6,75 \%$ (igual para ambas as composições de CAD). O teor de aditivo superplastificante considerado como ótimo foi de 1,6\% em relação à massa de cimento, uma vez que esse teor proporcionou um abatimento igual a $146 \mathrm{~mm}$, dentro do proposto inicialmente $(160 \mathrm{~mm} \pm 20 \mathrm{~mm})$, determinando-se, assim, a composição final do CAD otimizado com base no conceito de empacotamento de partículas (Tabela 4).

Tabela 4: Composição do CAD otimizado com base no conceito de empacotamento de partículas.

\begin{tabular}{|c|c|c|c|c|c|c|c|c|}
\hline \multicolumn{9}{|c|}{ Consumo de materiais $\left(\mathrm{kg} / \mathrm{m}^{3}\right.$ de concreto) } \\
\hline \multirow{2}{*}{ Cimento } & \multirow{2}{*}{$\begin{array}{l}\text { Sílica } \\
\text { ativa }\end{array}$} & \multicolumn{2}{|c|}{ Agregado miúdo } & \multicolumn{3}{|c|}{ Agregado graúdo } & \multirow{2}{*}{ Água } & \multirow{2}{*}{$\begin{array}{c}\text { Aditivo } \\
\text { superplastificante }\end{array}$} \\
\hline & & Areia média & Areia fina & Brita 1 & Pedrisco & Pó de pedra & & \\
\hline 362,3 & 120,8 & 362,3 & 241,5 & 724,5 & 241,5 & 362,3 & 163,0 & 5,80 \\
\hline
\end{tabular}

Observa-se nas Tabelas 2 e 4 que, com o emprego do conceito do empacotamento de partículas, a nova composição de CAD apresentou um menor consumo de cimento por metro cúbico de concreto, resultando em um material com menor impacto ambiental, ou seja, mais sustentável, pois a produção de cimento é responsável por emissões significativas de gases de efeito estufa, principalmente do dióxido de carbono $\left(\mathrm{CO}_{2}\right)$.

Na Tabela 5 são apresentadas, resumidamente, as características e propriedades do concreto de referência e do concreto otimizado com base no conceito de empacotamento de partículas.

Tabela 5: Características e propriedades dos concretos de alto desempenho.

\begin{tabular}{c|c|c}
\hline Concreto & CAD referência & CAD empacotamento \\
\hline Coeficiente de distribuição (q) & 0,29 & 0,29 \\
\hline Porosidade teórica (\%volume) & 21,7 & 12,2 \\
\hline Teor água/materiais secos (\%) & 6,75 & 6,75 \\
\hline Teor superplastificante/cimento (\%) & 1,0 & 1,6 \\
\hline Abatimento (mm) & 169 & 146 \\
\hline
\end{tabular}

\subsection{Análise das propriedades reológicas da pasta de cimento e da argamassa dos concretos de alto desempenho}

\subsubsection{Caracterização reológica das pastas de cimento}

Definidas as composições dos concretos, foi extraída uma amostra de pasta de cimento de cada concreto para a caracterização reológica. No ensaio reométrico, dentre os modelos reológicos para a caracterização das pastas de cimento, o que melhor se ajustou às curvas de escoamento obtidas no reômetro foi o modelo Newtoniano, sendo que os coeficientes de determinação $\left(\mathrm{R}^{2}\right)$ obtidos no modelo explicaram de 95,93 a 99,97\% dos 
dados observados. Trata-se de modelo a 1-parâmetro, no caso, o coeficiente de viscosidade ou comumente denominada viscosidade absoluta.

As viscosidades das pastas de cimento, obtidas aos 5, 15 e 30 minutos após a incorporação do superplastificante à mistura, são apresentadas na Tabela 6 .

Tabela 6: Viscosidades das pastas de cimento obtidas ao longo do tempo.

\begin{tabular}{c|c|c}
\hline \multirow{2}{*}{$\begin{array}{c}\text { Tempo após a incorporação do } \\
\text { superplastificante à mistura }\end{array}$} & $\begin{array}{c}\mid c \\
\text { Pasta de cimento } \\
\text { CAD referência }\end{array}$ & $\begin{array}{c}\text { Pasta de cimento } \\
\text { CAD empacotamento }\end{array}$ \\
\cline { 2 - 3 } & 0,161 & 0,144 \\
\hline $5 \mathrm{~min}$ & 0,172 & 0,146 \\
\hline $15 \mathrm{~min}$ & 0,187 & 0,150 \\
\hline $30 \mathrm{~min}$ & &
\end{tabular}

Na Tabela 6, observa-se que a pasta de cimento proveniente do CAD otimizado, com base no conceito de empacotamento de partículas, apresentou, ao longo do tempo, viscosidade praticamente constante e inferior à viscosidade da pasta de cimento do CAD de referência, indicando uma maior fluidez durante o tempo de análise. Isto pode ser associado ao significativo aumento do teor de aditivo superplastificante necessário para garantir a trabalhabilidade do concreto após a adição de novos materiais particulados. $\mathrm{O}$ aditivo superplastificante contribui com a dispersão das partículas de cimento, o que facilita o escoamento e, consequentemente, reduz a viscosidade da mistura [40,41]. Outro fator que pode ter influenciado o aumento da fluidez dessa pasta de cimento foi a redução da quantidade de cimento e o aumento do teor de sílica ativa, sendo que as partículas de sílica, quando bem dispersas, podem liberar a água presa entre as partículas de cimento aglomeradas e, assim, contribuir na fluidificação da mistura. Além disso, as partículas de sílica possuem formato esférico, o que reduz a fricção interparticular, contribuindo, assim, para o aumento da fluidez [41].

\subsubsection{Caracterização reológica das argamassas}

Foi extraída uma amostra de argamassa de cada composição de concreto para a caracterização reológica. No ensaio reométrico, dentre os modelos reológicos considerados para a caracterização do comportamento das argamassas, o que melhor se ajustou às curvas de escoamento obtidas com o reômetro foi o modelo Binghamiano, apresentando coeficientes de determinação $\left(R^{2}\right)$ variando de 97,07 a 98,65\%. Esse modelo fornece os dois parâmetros fundamentais para a caracterização reológica do material, isto é, a viscosidade plástica e a tensão limite de escoamento.

A viscosidade plástica e a tensão limite de escoamento das argamassas, obtidas aos 5, 30 e 60 minutos após a incorporação do superplastificante à mistura, são apresentadas nas Tabelas 7 e 8, respectivamente.

Tabela 7: Viscosidade plástica das argamassas obtida ao longo do tempo.

\begin{tabular}{c|c|c}
\hline \multirow{2}{*}{$\begin{array}{c}\text { Tempo após a incorporação do } \\
\text { superplastificante à mistura }\end{array}$} & $\begin{array}{c}\text { Viscosidade Plástica (Pa.s) } \\
\text { CAD referência }\end{array}$ & $\begin{array}{c}\text { Argamassa } \\
\text { CAD empacotamento }\end{array}$ \\
\cline { 2 - 3 } & 2,476 & 1,517 \\
\hline $5 \mathrm{~min}$ & 2,650 & 1,759 \\
\hline $30 \mathrm{~min}$ & 2,717 & 1,866 \\
\hline $60 \mathrm{~min}$ & &
\end{tabular}


Tabela 8: Tensão limite de escoamento das argamassas obtida ao longo do tempo.

\begin{tabular}{c|c|c}
\hline \multirow{2}{*}{$\begin{array}{c}\text { Tempo após a incorporação do } \\
\text { superplastificante à mistura }\end{array}$} & \multicolumn{2}{|c}{ Tensão limite de escoamento (Pa) } \\
\cline { 2 - 3 } & $\begin{array}{c}\text { Argamassa } \\
\text { CAD referência }\end{array}$ & $\begin{array}{c}\text { Argamassa } \\
\text { CAD empacotamento }\end{array}$ \\
\hline $5 \mathrm{~min}$ & 42,622 & 35,617 \\
\hline $30 \mathrm{~min}$ & 46,622 & 38,229 \\
\hline $60 \mathrm{~min}$ & 50,585 & 38,426 \\
\hline
\end{tabular}

Na Tabela 7, observa-se que a argamassa proveniente do CAD otimizado com base no conceito de empacotamento de partículas também apresentou, ao longo do tempo, viscosidade inferior à viscosidade da argamassa do CAD de referência; a mesma tendência de comportamento foi observada no que se refere à tensão limite de escoamento (ver Tabela 8). Essas características podem ser associadas ao aumento do teor de aditivo superplastificante, à diminuição da quantidade de cimento e ao aumento do teor de sílica ativa. Como já exposto, esses fatores facilitam o escoamento e contribuem com o aumento da fluidez da mistura.

\subsection{Análise da resistência à compressão dos concretos de alto desempenho}

As resistências à compressão do concreto de referência e do concreto, otimizado com base no conceito de empacotamento de partículas, obtidas nas idades de 3, 7 e 28 dias, são apresentadas na Tabela 9.

Tabela 9: Resistências à compressão dos concretos de alto desempenho ao longo do tempo.

\begin{tabular}{c|c|c|c|c}
\hline \multirow{2}{*}{$\begin{array}{c}\text { Idade } \\
\text { (dias) }\end{array}$} & $\begin{array}{c}\text { Resistência à compressão } \\
(\mathrm{MPa})\end{array}$ & $\begin{array}{c}\text { Desvio-padrão } \\
(\mathrm{MPa})\end{array}$ & $\begin{array}{c}\text { Resistência à compressão } \\
(\mathrm{MPa})\end{array}$ & $\begin{array}{c}\text { Desvio-padrão } \\
\text { (MPa) }\end{array}$ \\
\cline { 2 - 5 } & 49,1 & 1,4 & 33,0 & 1,7 \\
\hline 3 & 59,5 & 1,3 & 54,7 & 1,5 \\
\hline 7 & 64,0 & 3,0 & 73,4 & 1,2 \\
\hline 28 & Nota: os valores das resistências à compressão correspondem à média de 3 determinações \\
\hline
\end{tabular}

A Figura 10 apresenta a evolução da resistência à compressão dos concretos de alto desempenho ao longo do tempo.

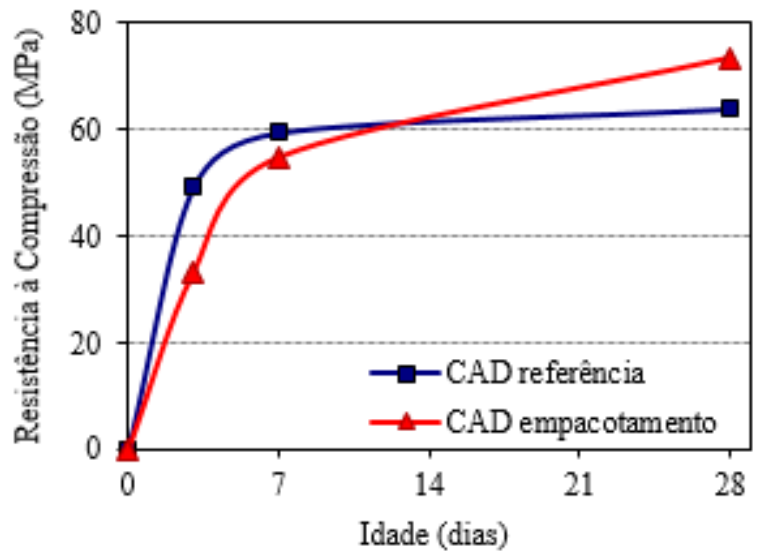

Figura 10: Evolução da resistência à compressão dos concretos de alto desempenho.

Observa-se na Figura 10 que o CAD de referência apresentou nas primeiras idades maiores resistências à compressão, porém, aos 28 dias, o CAD otimizado com base no conceito de empacotamento de partículas apresentou resistência à compressão superior. Tendência similar de comportamento foi observada por CASTRO et al. [33]. Nas primeiras idades, a menor resistência à compressão do CAD otimizado com base 
no conceito de empacotamento de partículas pode ser atribuída à menor quantidade de agregado graúdo (brita 1) utilizada nessa composição, quando comparada à composição do concreto de referência: esse material favorece o desempenho mecânico nas primeiras idades, enquanto nas idades mais avançadas há contribuição da matriz de partículas finas (pasta de cimento). Aos 28 dias, a maior quantidade de sílica ativa presente no CAD otimizado com base no conceito de empacotamento de partículas é responsável pelo fortalecimento da zona de transição na interface pasta/agregado, contribuindo com o aumento da resistência à compressão nessa idade. Além disso, a maior resistência desse concreto pode ser associada à presença de uma melhor distribuição de tamanho de partículas, que diminui a porosidade do sistema granular, melhorando o desempenho mecânico do concreto.

Destaca-se também que por meio do índice de intensidade de ligante, ou seja, relação entre o consumo de cimento $\left(\mathrm{kg} / \mathrm{m}^{3}\right.$ de concreto) por MPa de resistência à compressão aos 28 dias, conforme abordado por JOHN [42], o CAD otimizado, com base no conceito de empacotamento de partículas, apresentou índice de concreto sustentável igual a 4,94 kg. $\mathrm{m}^{-3} \cdot \mathrm{MPa}^{-1}$, enquanto o concreto de referência apresentou índice igual a $7,29 \mathrm{~kg} \cdot \mathrm{m}^{-3} \cdot \mathrm{MPa}^{-1}$.

\section{CONCLUSÕES}

Tendo em vista os resultados apresentados e discutidos ao longo deste artigo, é possível concluir:

- Composições dos concretos de alto desempenho

Para a produção do CAD, otimizado com base no conceito de empacotamento de partículas, foi necessário o emprego de novos materiais para preencher a ausência de determinados tamanhos de partículas existentes no CAD de referência. Além disso, após a otimização de seus componentes particulados, o empacotamento também demandou um aumento no teor de aditivo superplastificante para atender o abatimento inicialmente proposto $(160 \mathrm{~mm} \pm 20 \mathrm{~mm})$. O emprego do empacotamento de partículas proporcionou ao CAD redução de sua porosidade teórica, elevando sua resistência à compressão aos 28 dias.

- Análise das propriedades reológicas da pasta de cimento e da argamassa dos concretos de alto desempenho Tanto a pasta de cimento quanto a argamassa provenientes do CAD otimizado, com base no conceito de empacotamento de partículas, apresentaram-se mais fluidas, sendo seus parâmetros reológicos, como a viscosidade e a tensão limite de escoamento (apenas para a argamassa), menores quando comparados aos parâmetros da pasta e da argamassa provenientes do CAD de referência. $\mathrm{O}$ aumento da fluidez pode ter ocorrido pelo aumento do teor de aditivo superplastificante, que ajuda na dispersão, facilitando o escoamento. Este aumento foi necessário para manter a trabalhabilidade adequada do concreto, uma vez que o empacotamento aumentou significativamente, na mistura de concreto, a quantidade de materiais com granulometrias mais finas para uma quantidade fixa de água. A redução da quantidade de cimento e o aumento do teor de sílica ativa também podem ter provocado o aumento da fluidez da pasta e da argamassa, sabendo que as partículas de sílica ativa podem contribuir na fluidificação da mistura por meio da liberação da água presa entre as partículas de cimento aglomeradas. É importante salientar que a elevada fluidez da pasta e argamassa não prejudicou a estabilidade da mistura de CAD otimizado com base no conceito de empacotamento de partículas, não sendo evidenciada a ocorrência de segregação e exsudação nesse concreto.

- Análise da resistência à compressão dos concretos de alto desempenho

O CAD otimizado, com base no conceito de empacotamento de partículas, quando comparado ao CAD de referência, apresentou resistência à compressão superior na idade de 28 dias, podendo este resultado ser associado à presença de uma melhor distribuição granulométrica que reduz a porosidade do concreto, aumentando, assim, seu desempenho mecânico. Destaca-se que houve dificuldade na otimização das partículas, principalmente na fração mais fina, devido à falta de materiais com granulometrias adequadas necessárias a um custo acessível para a produção de concretos aplicados na prática da construção, impedindo o aumento da eficiência do empacotamento que, por sua vez, implicaria em incrementos ainda mais significativos da resistência à compressão do CAD em idades avançadas. O CAD otimizado, com base no conceito de empacotamento de partículas, também apresentou menor índice de intensidade de ligante, podendo ser considerado um concreto mais sustentável que o CAD de referência. 


\section{AGRADECIMENTOS}

Os autores agradecem à Coordenação de Aperfeiçoamento de Pessoal de Nível Superior (CAPES) pelo apoio financeiro, aos Laboratórios CESP de Engenharia Civil e da UNESP/Ilha Solteira pela disponibilidade e auxílio, à Associação Brasileira de Cimento Portland $(\mathrm{ABCP})$ por realizar os ensaios de granulometria a laser, às empresas Holcim Brasil S.A., Elkem Materials South America Ltda., Grace Construction Products e Mineração Jundu Ltda. pela doação dos materiais utilizados na pesquisa.

\section{BIBLIOGRAFIA}

[1] FERRARIS, C.F., OBLA, K.H., HILL, R., "The influence of mineral admixtures on the rheology of cement paste and concrete", Cement and Concrete Research, v. 31, n. 2, pp. 245-255, 2001.

[2] AL-MARTINI, S., NEHDI, M., "Genetic algorithm rheological equations for cement paste", Proceedings Of The Institution Of Civil Engineers, v. 163 , n. 2 , pp. 77-85, 2010.

[3] KONG, X., ZHANG, Y., HOU, S., "Study on the rheological properties of Portland cement pastes with polycarboxylate superplasticizers", Rheologica Acta, v. 52, n. 7, p. 707-718, 2013.

[4] LI, B. et al., "Investigation of the rheological properties of cement paste with different superplasticisers based on colour function and RDS methods", Advances in Cement Research, v. 28, n. 6, p. 357-370, 2016.

[5] BANFILL, P.F.G. “A coaxial cylinders viscosimeter for mortar: design and experimental validation”, In: Banfill, P.F.G. (ed), Rheology of Fresh Cement and Concrete, London, E \& FN Spon, 1991.

[6] TATTERSALL, G.H., "Application of rheological measurements to practical control of concrete". In: Banfill, P.F.G. (ed), Rheology of Fresh Cement and Concrete, London, E \& FN Spon, 1991

[7] De LARRARD, F., FERRARIS, C.F., SEDRAN, T., "Fresh concrete: a Herschel-Bulkley material", $M a-$ terials and Structures, v. 31, n. 7, pp. 494-498, 1998.

[8] AÏTCIN, P.C., High performance concrete, London, E\&FN SPON, 1998.

[9] ROUSSEL, N., Understanding the rheology of concrete, Woodhead Publishing Limited, 2012.

[10] GHODDOUSI, P., JAVID, A.A.S., SOBHANI, J., "Effects of particle packing density on the stability and rheology of self-consolidating concrete containing mineral admixtures", Construction and Building Materials, v. 53, pp. 102-109, 2014.

[11] FERRARIS, C.F., "Measurement of rheological properties of high performance concrete: state of the art report”, Journal of Research of the National Institute of Standards and Technology, v. 104, n. 5, pp. 461-478, 1999.

[12] BANFILL, P. F. G., "Additivity effects in the rheology of fresh concrete containing water-reducing admixtures", Construction and Building Materials, v. 25, n. 6, pp. 2955-2960, 2011.

[13] FERRARIS, C. F., MARTYS, N.S., Concrete rheometers, In: ROUSSEL, N. (Ed.). Understanding the rheology of concrete. Cambridge: Woodhead Publishing Limited, 2012.

[14] LARRARD, F., HU, C., SEDRAN, T., et al, "A new rheometer for soft-to-fluid concrete", ACI Materials Journal, v. 94, n. 3, pp. 234-243, 1997.

[15] PILEGGI, R.G., PAIVA, A.E., GALlO, J., PANDOLFELLI, V.C., "Novel rheometer for refractory castables", American Ceramic Society Bulletin, v. 79, n. 1, pp. 54-58, 2000.

[16] FERRARIS, C.F., BROWER, L., BEAUPRE, D., et al., Comparison of concrete rheometers: international tests at LCPC (Nantes, France) in October, 2000, NISTIR 6819, 2001.

[17] CASTRO, A.L., LIBORIO, J.B.L., PANDOLFELLI, V.C. "Evaluation of fresh high performance concrete behavior by rheometer assistance", IBRACON Structures and Materials Journal, v. 2, n. 4, pp. 282-305, 2009.

[18] BARBOSA, M.P., MACIEL, G.F., CASTRO, A.L., REIS, J.F.A., LEMOS, K.A.A., "Determination of rheological parameters of mortar and concrete by alternative techniques", IBRACON Structures and Materials Journal, v. 4, n. 3, pp. 440-480, 2011.

[19] GIROTTO, L.S., BARBOSA, M.P., MACIEL, G.F. "Rheological behavior study of plastic shrinkage and cracking of self-compacting concrete mortars", IBRACON Structures and Materials Journal, v. 7, n. 1, pp. 24-52, 2014.

[20] TUTIKIAN, B.F., HELENE, P. "Dosagem dos concretos de cimento Portland". In: Isaia, G.C. (ed), Concreto: ciência e tecnologia, capítulo 12, São Paulo, IBRACON, 2011. 
[21] TATTERSALL, G.H., BANFILL, P.F.G., The rheology of fresh concrete, London, Pitman, 1983.

[22] PETROU, M.F., HARRIES, K.A., GADALA-MARIA, F., KOLLI, V.G., "A unique experimental method for monitoring aggregate settlement in concrete", Cement and Concrete Research, v. 30, n. 5, pp. 809-816, 2000.

[23] STROEVEN, P., STROEVEN, M., "SPACE system for simulation of aggregated matter application to cement hydration", Cement and Concrete Research, v. 29, n. 8, pp. 1299-1304, 1999.

[24] OLIVEIRA, I.R., STUDART, A.R., PILEGGI, R.G., et al., Dispersão e empacotamento de partículas: princípios e aplicações em processamento cerâmico, São Paulo, Fazendo Arte, 2000.

[25] LARRARD, F., SEDRAN, T., "Mixture-proportioning of high-performance concrete", Cement and Concrete Research, v. 32, n. 11, pp. 1699-1704, 2002.

[26] AIQIN, W., CHENGZHI, Z., NINGSHENG, Z., "Study of the influence of the particle size distribution on the properties of cement", Cement and Concrete Research, v. 27, n. 5, pp. 685-695, 1997.

[27] CASTRO, A., FERREIRA, F., "Effect of particle packing in the durability of high performance concretes", Revista Ingeniería de Construcción, v. 31, n. 2, pp. 104, 2016.

[28] FUNK, J.E., DINGER, D., Predictive process control of crowded particulate suspensions: applied to ceramic manufacturing. New York, Springer Science \& Business Media, 1994.

[29] PEREIRA, T.A.C., LIBORIO, J.B.L., "Técnicas de empacotamento de partículas para obtenção de CAD”, In: Anais do $51^{\circ}$ Congresso Brasileiro do Concreto, Curitiba, Out. 2009.

[30] VANDERLEI, R.D., Análise experimental do concreto de pós reativos: dosagem e propriedades mecânicas, Tese de D.Sc., Universidade de São Paulo, São Carlos, SP, Brasil, 2004.

[31] PILEGGI, R.G., Efeito da distribuição granulométrica sobre o comportamento reológico de concretos refratários, Dissertação de M.Sc., Universidade Federal de São Carlos, São Carlos, SP, Brasil, 1996.

[32] LARRARD, F., Concrete mixture proportioning: a scientific approach, London, E \& FN Spon; 1999.

[33] CASTRO, A.L., LIBORIO, J.B.L., PANDOLFELLI, V.C. "Desempenho de concretos avançados para a construção civil, formulados a partir do método de dosagem computacional", Cerâmica, v. 55, n. 335, pp. 233-251, 2009.

[34] OLIVEIRA, C. O., Análise das propriedades reológicas de materiais cimentícios associando o conceito de empacotamento de partículas, Dissertação de M.Sc., Universidade Estadual Paulista, Ilha Solteira, SP, Brasil, 2013.

[35] CASTRO, A.L., PANDOLFELLI, V.C., "Revisão: Conceitos de dispersão e empacotamento de partículas para a produção de concretos especiais aplicados na construção civil”, Cerâmica, v. 55, n. 333, pp. 18-32, 2009.

[36] OLIVEIRA, C.O., BARBOSA, M.P., MACIEL, G.F., et al., "Dosagem de um concreto de alto desempenho utilizando os conceitos de reologia", In: Anais do $55^{\circ}$ Congresso Brasileiro do Concreto, Gramado, Out. 2013.

[37] REIS, J.F.A., Determinação de parâmetros reológicos de concretos através do ensaio de abatimento de tronco de cone modificado: estudo de caso, Dissertação de M.Sc., Universidade Estadual Paulista, Ilha Solteira, SP, Brasil, 2008.

[38] ASSOCIAÇÃO BRASILEIRA DE NORMAS TÉCNICAS. NBR NM 67: Concreto - Determinação da consistência pelo abatimento do tronco de cone, Rio de Janeiro, 1998.

[39] ASSOCIAÇÃO BRASILEIRA DE NORMAS TÉCNICAS. NBR 5739: Concreto - Ensaios de compressão de corpos de prova cilíndricos, Rio de Janeiro, 2007.

[40] ZHANG, Y., KONG, X., GAO, L., et al., "Rheological behaviors of fresh cement pastes with polycarboxylate superplasticizer", Journal of Wuhan University of Technology-Mater. Sci. Ed., v. 31, n. 2, pp. 286$299,2016$.

[41] SAKAI, E., KAKINUMA, Y., YAMAMOTO, K., et al., "Relation between the shape of silica fume and the fluidity of cement paste at low water to powder ratio", Journal of Advanced Concrete Technology, v. 7, n. 1, pp. 13-20, 2009.

[42] JOHN, V.M., "Concreto Sustentável", In: Isaia, G.C. (ed), Concreto: ciência e tecnologia, cap. 50, São Paulo, IBRACON, 2011. 